\title{
Pseudomonas aeruginosa Toxin ExoU as a Therapeutic Target in the Treatment of Bacterial Infections
}

\author{
Daniel M. Foulkes ${ }^{1,2, *}$, Keri McLean ${ }^{1,3, *}$ (i) , Atikah S. Haneef ${ }^{1}$, David G. Fernig ${ }^{2}$, \\ Craig Winstanley ${ }^{4}$, Neil Berry ${ }^{5}(\mathbb{D})$ and Stephen B. Kaye ${ }^{1,3(D)}$ \\ 1 Department of Eye and Vision Science, Institute of Ageing and Chronic Disease, University of Liverpool, \\ Liverpool L7 8TX, UK; atikahh@liverpool.ac.uk (A.S.H.); sbkaye@liverpool.ac.uk (S.B.K.) \\ 2 Department of Biochemistry, Institute of Integrative Biology, University of Liverpool, Liverpool L69 7ZB, UK; \\ dgfernig@liverpool.ac.uk \\ 3 St. Paul's Eye Unit, Royal Liverpool University Hospital, Liverpool L7 8XP, UK \\ 4 Department of Clinical Infection, Institute of Infection and Global Health, University of Liverpool, \\ Liverpool L6 97B, UK; cwinstan@liverpool.ac.uk \\ 5 Department of Chemistry, University of Liverpool, Liverpool L69 7ZD, UK; ngberry@liverpool.ac.uk \\ * Correspondence: daniel.foulkes@liv.ac.uk (D.M.F.); hlkmclea@liverpool.ac.uk (K.M.)
}

Received: 16 October 2019; Accepted: 14 December 2019; Published: 16 December 2019

\begin{abstract}
The opportunistic pathogen Pseudomonas aeruginosa employs the type III secretion system (T3SS) and four effector proteins, ExoS, ExoT, ExoU, and ExoY, to disrupt cellular physiology and subvert the host's innate immune response. Of the effector proteins delivered by the T3SS, ExoU is the most toxic. In P. aeruginosa infections, where the ExoU gene is expressed, disease severity is increased with poorer prognoses. This is considered to be due to the rapid and irreversible damage exerted by the phospholipase activity of ExoU, which cannot be halted before conventional antibiotics can successfully eliminate the pathogen. This review will discuss what is currently known about ExoU and explore its potential as a therapeutic target, highlighting some of the small molecule ExoU inhibitors that have been discovered from screening approaches.
\end{abstract}

Keywords: Pseudomonas aeruginosa; ExoU; type 3 secretion system; inhibitor; non-antibiotic antimicrobials

\section{Introduction}

Pseudomonas aeruginosa is a motile, Gram-negative rod-shaped bacterium that causes a wide range of opportunist infections including corneal, soft tissue, urinary tract, and respiratory tract infections; often with high rates of morbidity and mortality [1-5]. It is a major cause of intensive care unit-acquired pneumonia (ICUAP), as well as a known coloniser of patients with cystic fibrosis and those who are immunocompromised [6-8]. Furthermore, multidrug-resistant P. aeruginosa is a major threat, as recently highlighted when the World Health Organisation (WHO) listed carbapenem-resistant P. aeruginosa as the highest priority for the development of new antibiotics [9]. It is, therefore, imperative that efforts are made to develop novel treatments to target this pathogen.

P. aeruginosa produces numerous virulence factors (Table 1) along with a complex regulatory network of intra- and inter-cellular signals allowing it to adapt, thrive, and escape host defences [10]. In particular, the Type-III secretion systems (T3SS) has been identified as a major virulence determinant for poor clinical outcomes in intensive care unit (ICU)-acquired pneumonia (ICUAP), keratitis (infection of the cornea), and otitis externa (infection of the ear canal) [4,5,11-13]. The T3SS comprises needle-like, membrane-anchored, multi-component complexes on certain pathogenic bacteria-including Pseudomonas, Salmonella, Shigella, and Yersina spp.- that inject effectors from the 
bacteria's cytosol directly into the cytoplasm of the eukaryotic host cell [14]. There are four distinct exoenzymes that $P$. aeruginosa employs to project virulence and which are injected into the target host cell via the T3SS: ExoS, ExoT, ExoU, and ExoY.

Table 1. Important virulence effectors of Pseudomonas aeruginosa in mammalian infection.

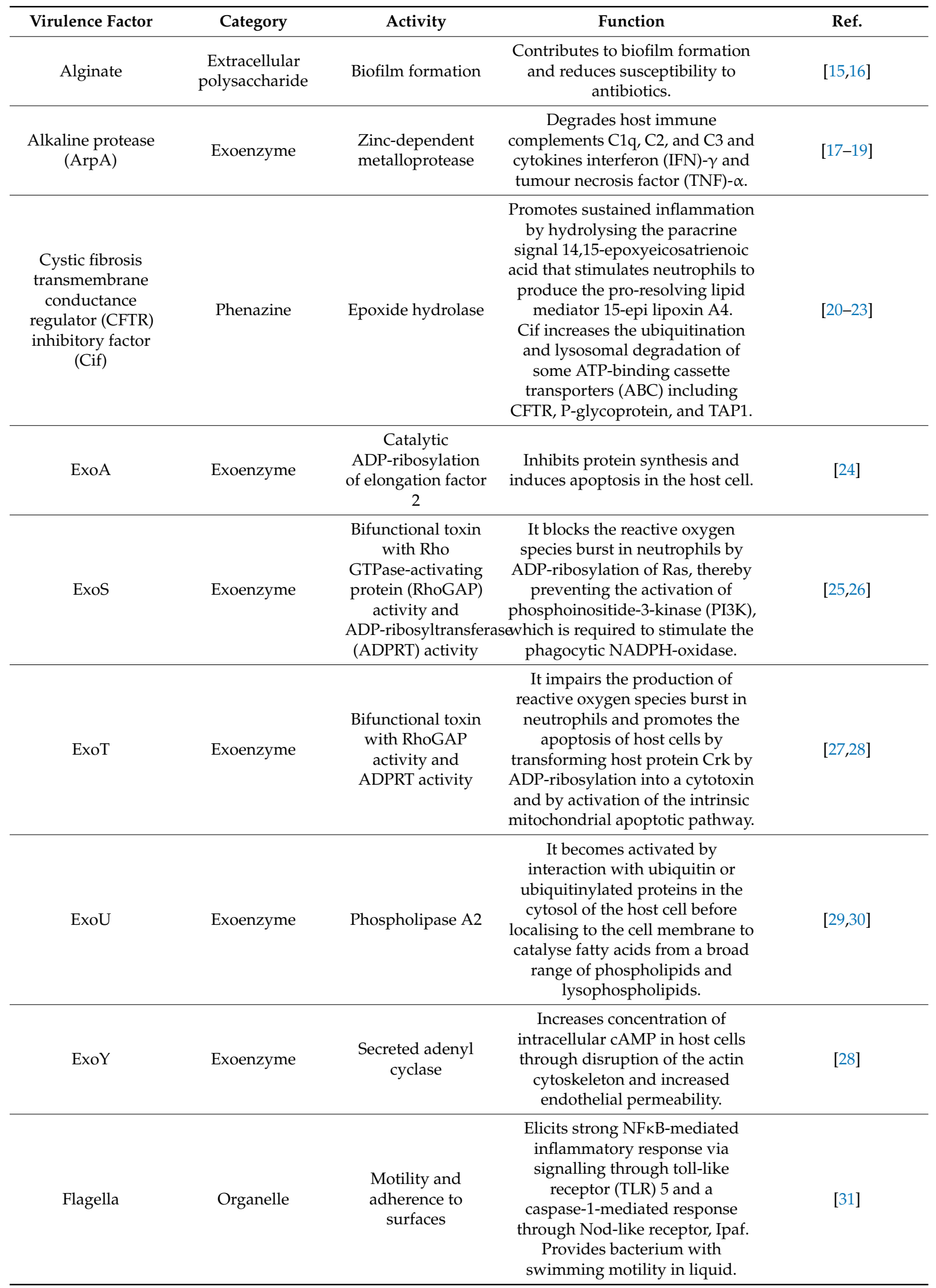


Table 1. Cont.

\begin{tabular}{|c|c|c|c|c|}
\hline Virulence Factor & Category & Activity & Function & Ref. \\
\hline LasA & Exoenzyme & $\begin{array}{l}\text { Metallopeptidase, } \\
\text { also known as } \\
\text { staphylolysin }\end{array}$ & $\begin{array}{c}\text { LasA acts with restricted } \\
\text { specificity, predominantly at } \\
\text { glycine-glycine peptide bonds, } \\
\text { but also increases the elastinolytic } \\
\text { activity of LasB. }\end{array}$ & {$[32]$} \\
\hline LasB & Exoenzyme & Zinc-metalloprotease & Causes elastin degradation. & {$[17,33]$} \\
\hline $\mathrm{PlcH}$ & Exoenzyme & $\begin{array}{c}\text { Haemolytic } \\
\text { phospholipase C }\end{array}$ & $\begin{array}{l}\text { Releases phosphate esters from } \\
\text { sphingomyelin and } \\
\text { phosphatidylcholine. }\end{array}$ & [34] \\
\hline $\mathrm{PlcN}$ & Exoenzyme & $\begin{array}{l}\text { Non-haemolytic } \\
\text { phospholipase C }\end{array}$ & $\begin{array}{c}\text { Releases phosphate esters from } \\
\text { phosphatidylserine and } \\
\text { phosphatidylcholine. }\end{array}$ & [35] \\
\hline PldA and PldB & Exoenzyme & Phospholipase D & $\begin{array}{l}\text { Facilitates intracellular invasion of } \\
\text { host eukaryotic cells by activation } \\
\text { of the PI3K/ Akt pathway. }\end{array}$ & {$[36,37]$} \\
\hline PrpL & Exoenzyme & $\begin{array}{l}\text { Class IV protease, } \\
\text { lysine } \\
\text { endoproteinase }\end{array}$ & $\begin{array}{l}\text { Inactivates a range of host } \\
\text { defences including fibrinogen, } \\
\text { plasminogen, immunoglobulin } \mathrm{G} \text {, } \\
\text { and complement proteins } \mathrm{C} 1 \mathrm{q} \text { and } \\
\text { C3. }\end{array}$ & {$[38,39]$} \\
\hline Pyocyanin & Phenazine & $\begin{array}{l}\text { Redox-active } \\
\text { zwitterion }\end{array}$ & $\begin{array}{l}\text { Inhibits host cell respiration, } \\
\text { ciliary function, and epidermal } \\
\text { growth; disrupts calcium } \\
\text { homeostasis and induces } \\
\text { apoptosis in neutrophils. }\end{array}$ & {$[40]$} \\
\hline Rhamnolipids & Surfactant & Biosurfactants & $\begin{array}{l}\text { Participates in the maintenance of } \\
\text { uninhabited channels } \\
\text { surrounding biofilm communities, } \\
\text { which serve to provide nutrients } \\
\text { and oxygen to the colonies of } \\
\text { bacteria. } \\
\text { Biofilms can form on implants and } \\
\text { on dead or living tissue. They are } \\
\text { inherently difficult to eradicate } \\
\text { with antibiotics due to the } \\
\text { inability of antibiotic molecules to } \\
\text { penetrate the extracellular matrix. }\end{array}$ & {$[41]$} \\
\hline TplE & Exoenzyme & Phospholipase A1 & $\begin{array}{l}\text { Disrupts the endoplasmic } \\
\text { reticulum and thereby promotes } \\
\text { autophagy by the activation of the } \\
\text { unfolded protein response. }\end{array}$ & {$[42]$} \\
\hline
\end{tabular}

P. aeruginosa isolates can be broadly categorised into those that carry the gene for ExoS or those that carry the gene for ExoU. Expression of these two exotoxins is almost mutually exclusive and strains of P. aeruginosa encoding both or neither are rare [43]. ExoU and ExoS facilitate distinctive mechanisms of bacterial propagation and pathogenesis, which may reflect why they are not cooperatively expressed [43]. While ExoS expression has been associated with endocytic uptake and intracellular survival of bacteria, ExoU expression mediates rapid destruction of the host cell plasma membrane. Endocytic uptake, mediated by ExoS, refers to internalisation of the P. aeruginosa, by the host cell, through the invagination of the plasma membrane and the formation of membrane vesicles, in which the bacteria can survive.

ExoS is a bi-functional molecule with an N-terminal GTPase-activating (GAP) domain and a C-terminal ADP-ribosyltransferase domain [44]. It blocks the reactive oxygen species burst in neutrophils by ADP-ribosylation of Ras, thereby preventing the activation of phosphoinositide-3-kinase (PI3K), which is required to stimulate the phagocytic NADPH-oxidase [45]. Injection of ExoS into the target cell also alters the cell cytoskeleton, resulting in cell rounding, inhibition of phagocytosis, which eventually leads to apoptotic cell death [46]. 
ExoU possesses potent phospholipase activity, which causes rapid cell lysis and necroptosis in epithelial cells, macrophages, and neutrophils [29,47-50]. Furthermore, the depletion of neutrophils leads to an immunosuppressive effect that makes the host more susceptible to secondary infections [50,51]. In comparison to strains expressing ExoS, ExoU-expressing P. aeruginosa have been associated with more severe outcomes in keratitis, acute pneumonia, and ICUAP [5,8,43,52].

Given its contribution to clinical severity, therapeutic targeting of ExoU could perhaps attenuate the morbidity and mortality of acute P. aeruginosa infections. This review focuses on ExoU; exploring its mechanism of action, as well as the current knowledge about small molecules that have the potential to be developed as inhibitors of ExoU in disease.

\section{Exotoxin $U$}

ExoU is a $74-\mathrm{kDa}$ (687-amino acid) soluble protein that possesses an $\mathrm{N}$-terminal bacterial chaperone interacting domain followed by a patatin-like phospholipase (PLP) domain and finally C-terminus containing a 4-helic bundle, which is employed for insertion into plasma membranes [29,47,48,53]. It was discovered in vitro and in vivo that ExoU translocation, alone, into mammalian host cells via the T3SS results in rapid cellular necroptosis due to ExoU phospholipase activity directed towards the plasma membrane [47,54-57]. Although the mechanisms of ExoU activation have yet to be fully explored, it is understood that certain eukaryotic host co-factors directly interact with ExoU and are required for catalytic phospholipase activity to be induced. In-vitro phospholipase activity of recombinant ExoU was only first apparent in the presence of mammalian cell lysate, which indicated that eukaryotic co-factors are required for enzymatic activity [29,48]. Subsequently, ExoU was reported to be activated by the protein superoxide dismutase 1 (SOD1) in vitro [58]. However, it was later discovered that ubiquitinated SOD1, in commercial extracts, was responsible for the activation of ExoU [59]. Ubiquitin polymers, of several linkage types, including linear diubiquitin, have been shown to greatly enhance the ability to bind to and activate ExoU compared to monomeric forms [30]. When ubiquitin and ExoU are co-expressed in Escherichia coli, rapid degradation of the bacterial membrane and cell death can be observed, suggesting that ubiquitin is indeed a necessary activating co-factor [30,60].

When bound to SpcU, ExoU is inactive, and in the absence of activating eukaryotic co-factors, ExoU expression is not lethal to the P. aeruginosa. SpcU is a 137 amino acid, curved, 5-stranded sheet flanked by alpha-helices, which binds to ExoU at the N-terminus [61]. As well as maintaining ExoU in an inactive state, $\mathrm{SpcU}$ guides ExoU to the T3SS machinery, for appropriate secretion. SpcU allows ExoU to unfold and pass through the needle of the T3SS [62,63] but does not enter the host cell along with ExoU [14]. After injection, ExoU is activated by binding to ubiquitin before it localises to the plasma membrane where it oligomerises and exerts its phospholipase activity (Figure 1) [48,64].

Sequence alignments of ExoU, patatins (Arabidopsis thaliana Patatin-like protein 1), mammalian calcium-dependent cytosolic $\mathrm{PLA}_{2}\left(\mathrm{cPLA}_{2}\right)$, and calcium-independent $\mathrm{PLA}_{2}\left(\mathrm{iPLA}_{2}\right)$ enzymes demonstrate homology in three highly conserved regions; a glycine-rich nucleotide-binding motif between amino acids 111-116, a catalytic serine motif spanning amino acid 140-144, and an active site

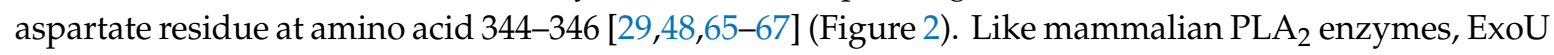
relies on an indispensable catalytic dyad of serine $\left(\mathrm{Ser}_{142}\right)$ and aspartic acid $\left(\mathrm{Asp}_{344}\right)$ [29]. Mutation of either of these residues to an alanine renders the protein inactive in vitro, as well as the abolition of ExoU mediated cytotoxicity in vivo [29]. 


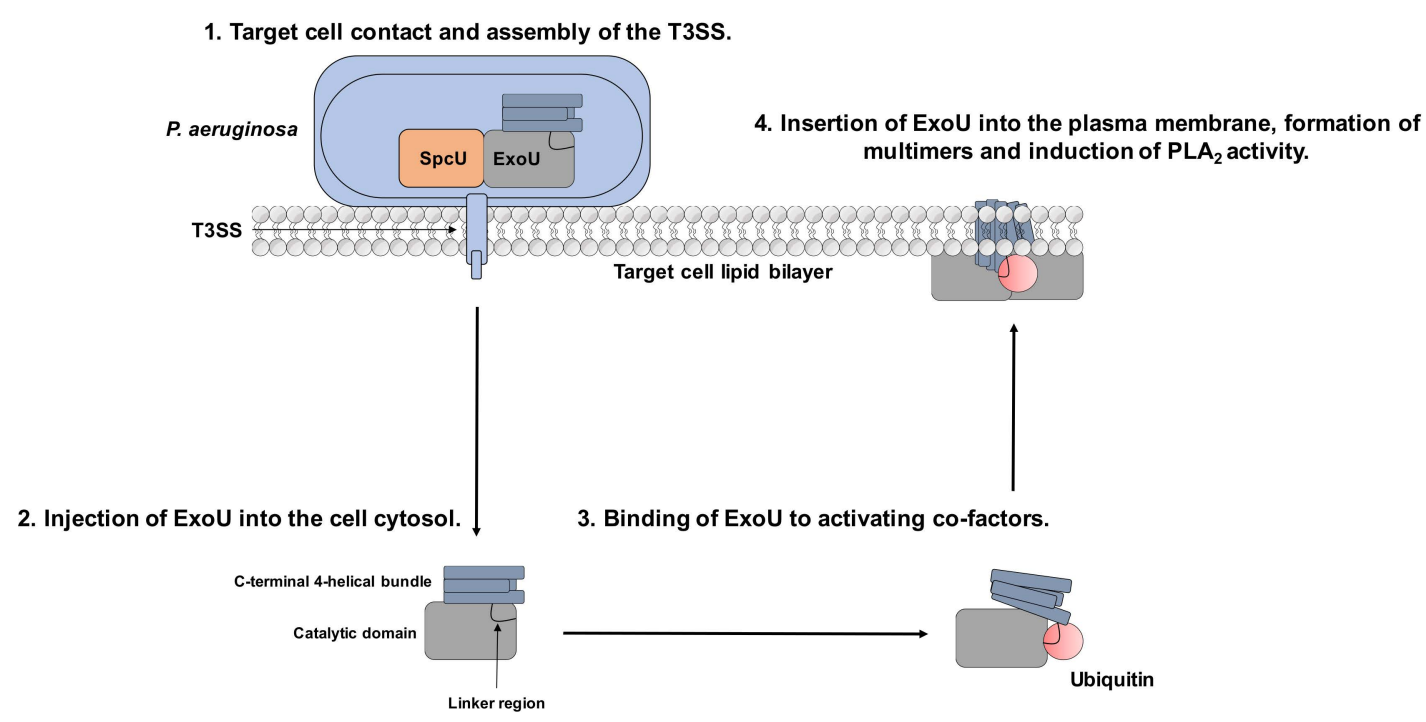

Figure 1. Mechanism of ExoU toxicity and potential for targeting with small molecules. 1. P. aeruginosa binds to the target cell, which stimulates T3SS assembly. 2. ExoU is injected to the host cell via the T3SS. 3. Once in the cellular cytoplasm, it interacts with the eukaryotic host co-factor ubiquitin. 4. ExoU localises to the plasma membrane and oligomerises to stimulate full catalytic activity, leading to cellular lysis. The linker region links the catalytic domain to the 4-helical membrane localisation domain (MLD) and is the proposed binding site for ubiquitin. The 4-helical MLD domain is in the C-terminus of the protein and is responsible for interaction with $\mathrm{PIP}_{2}$ and insertion into the host cell plasma membrane. Compounds that could potentially subvert ExoU mediated cytotoxicity could: prevent ExoU secretion from $P$. aeruginosa, bind to the substrate-binding site in the catalytic domain, prevent ubiquitin-binding, or inhibit multimerisation and association with PIP2.

The crystal structure of ExoU in complex with its cognate chaperone SpcU was solved in $2012[64,68]$ (PDB entry numbers 3TU3 and 4AKX). A PLA 2 (phospholipase) domain between residues 102-471 that contains the active site as well as a flexible region known as the active site 'cap' between Pro 320 and Leu 328, which suggests that conformational rearrangement is required for enzymatic activity $[64,68]$. The structure reveals that the catalytic domain of ExoU is structurally similar to human CPLA 2 and plant patatin PLA 2 enzymes [64,68]. The four-helix bundle membrane localisation domain (MLD) of the C-terminus appears to share common structural elements in the targeting of a wide variety of diverse bacterial toxins to the membrane interface. These include clostridial glucosylating toxins, MARTX toxins, and Pasteurella multocida-like toxins [69,70]. 
Glycine rich motif (G-X-G-X-X-G/A)

Catalytic Serine motif (G-X-S-G/S)

Pseudomonasaeruginosa ExoU(1-687) 108 VLSGGG AKGAA. YP PGAMLALEEKGM. DOIRSMSOSSAGO. ITAALLASGM....SPAAF Homo sapienscPLA2 GIVA (1-749) 193 LGSGGGFRAMV GF SGVMKAL

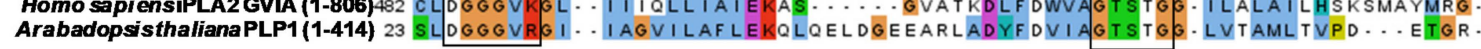

\section{Active site Aspartic acid motif (D-X-G/A)}

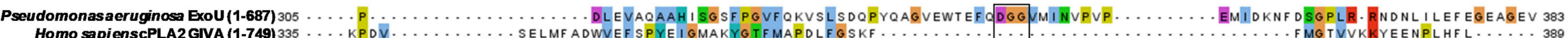

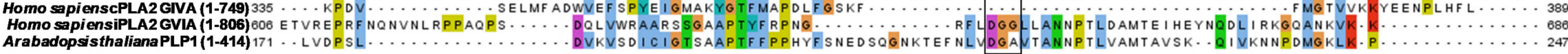

Figure 2. Amino acid alignment of P. aeruginosa ExoU, human cPLA 2 GIVA, human iPLA 2 GVIA and Arabidopsis thaliana PLP1. The full-length sequences of ExoU (uniprot O34208), human cPLA 2 \& GIVA (uniprot P47712), human iPLA 2 GVIA (uniprot O60733), and Arabidopsis thaliana Patatin-like protein 1 (PLP1) (uniprot O23179) were aligned using the TcoffeeWS multiple sequence alignment tool and visualised in Jal view. The glycine-rich, catalytic serine and catalytic aspartic acid motifs are shown in black boxes. 


\subsection{Secretion of ExoU via the T3SS}

The structure of the T3SS comprises a macromolecular complex spanning the bacterium's internal membrane, periplasmic space, peptidoglycan layer, outer membrane, then the extracellular space and the target cell membrane [71,72]. Upon contact with the target cell, a translocation pore can form across the host cell membrane, allowing the T3SS injectisome to actively secrete the exotoxins from the bacterial cytosol into the host cytosol under the influence of ATPases [14,73-75]. The T3SS injectisome has a narrow lumen of approximately $25-40 \AA$ diameter, formed by an assembly of helical PscF proteins $[72,76,77]$; thus, the exotoxins have to unfold to pass through the channel. The mechanism by which ExoU refolds once inside the host cytoplasm is unknown.

\subsection{Control of T3SS Gene Expression}

Expression of the T3SS is a controlled response to particular environmental stimuli, such as host cell contact and low levels of extracellular calcium ions [78]. Expression is controlled principally by the interactions of four transcription factors: ExsA, ExsC, ExsD, and ExsE, with transcription factor ExsA considered to be the master regulator [79]. The injectisome, in non-inducing conditions, is expressed at a basal level and is the sensor of inducing signals. In response to host cell contact or low levels of calcium ions, the injectisome converts to a secretion-competent state through an unclear mechanism [79]. In non-inducing circumstances, the transcription factor ExsE remains cytoplasmic in a 1:2 complex with ExsC [80], with ExsA is sequestered by ExsD in a 1:1 complex [81]. However, in inducing conditions, ExsE dissociates from ExsC and translocates through the injectisome [82]. This causes ExsC to bind to ExsD in a 2:2 complex, resulting in the release of ExsA [83], which then targets T3SS promoters to upregulate expression.

\subsection{Oligomerisation and Localisation to the Host Cell Wall in the Presence of Phosphatidylinositol 4,5-Bisphosphate $\left(\right.$ PIP $\left._{2}\right)$}

Following translocation into the target cell, ExoU binds to ubiquitin and localises to the plasma membrane by its interaction with phosphatidylinositol 4,5-bisphosphate $\left(\mathrm{PIP}_{2}\right)$ [84-86]. $\mathrm{PIP}_{2}$ is a biologically important phospholipid in eukaryotic cells, which mostly resides in the inner plasma membrane at relatively low concentrations ( 1\%) [87]. It is involved in cell signalling pathways, which govern cell adhesion, mobility, cytoskeletal organisation and dynamics, and membrane trafficking [88-91]. Additionally, it directly binds to focal adhesion molecules, such as talin and vinculin, and other adaptor proteins that have a crucial role in cell-matrix and cell-cell adhesion [90,91].

The C-terminal MLD of ExoU, containing the four-helical bundle, has a high binding affinity for $\mathrm{PIP}_{2}[68,92]$. Models suggest that binding to $\mathrm{PIP}_{2}$ causes conformation changes in the structure of ExoU, including the conformational rearrangement of the four-helical bundle of ExoU, allowing it to insert into the lipid membrane $[84,93]$. $\mathrm{PIP}_{2}$ binding has also been demonstrated to promote ExoU multimerisation [93]. SEC-MALS analysis and phospholipase assays indicate that, in vitro, in the presence $\mathrm{PIP}_{2}$, ExoU can form multimers that have greatly enhanced catalytic activity, in the presence of ubiquitin, when compared to ExoU and ubiquitin alone [93].

Following binding to $\mathrm{PIP}_{2}$, ExoU hydrolyses the substrate with a dose-dependent effect on ExoU-mediated cytotoxicity $[68,86,92]$. A HeLa cell infection model demonstrated that the addition of exogenous $\mathrm{PIP}_{2}$ increased ExoU-mediated cytotoxicity [92]. As $\mathrm{PIP}_{2}$ co-activates ExoU and enhances in vitro phospholipase activity in the presence of ubiquitin $[60,86]$, it has been postulated that ExoU utilises $\mathrm{PIP}_{2}$ to engage the plasma membrane and hydrolyse adjacent substrate phospholipids more efficiently [59,94]. Time-lapse fluorescent image analysis of infected HeLa cells demonstrated that ExoU intoxication correlates with significant intracellular changes leading to necroptosis. Early stages of ExoU intoxication cause disruption of focal adhesions and linkages between integrins, the actin cytoskeleton and the cell membrane, which leads to cell detachment, cytoskeletal collapse, and cell rounding. Subsequently, $3.5 \mathrm{~h}$ after infection, membrane blebbing becomes apparent, followed by the loss of plasma membrane integrity, function, and rupture [92]. 


\subsection{Interactions with Host Cell Signalling Pathways}

It has been suggested that ExoU, as well as inducing cell lysis of the target cell, attenuates particular cellular signalling pathways (Figure 3) [95]. Cuzick et al. demonstrated in a human bronchial cell line that ExoU-producing P. aeruginosa could activate the c-Jun $\mathrm{NH}_{2}$ terminal kinase (JNK) mitogen-activated protein kinase (MAPK) pathway, resulting in increased production of active AP-1 transcription factor [96]. These findings complement the earlier discovery by McMorran et al., that ExoU-producing P. aeruginosa induced the early and transient up-regulation of gene expression in the AP1 transcription factor complex [97]. Cuzick et al., in the same study, demonstrated that catalytically active ExoU, but not the catalytic dead (S142A), significantly increased IL-8 production, suggesting this results from activation of the JNK/MAPK pathway [96]. IL-8 is an important pro-inflammatory chemokine that attracts neutrophils. Effects of neutrophil recruitment could be imported for bacterial clearance; however, ExoU could cause neutrophils to mediate tissue damage and subvert the innate immune response by increasing epithelial cell permeability and, in turn, potentiate invasion of the bacteria [96]. ExoU-positive P. aeruginosa has also been shown to trigger the arachidonic acid-dependent inflammatory cascade, inducing a significant release of prostacyclins, $\mathrm{PGE}_{2}$ and $\mathrm{PGI}_{2}$ (prostacyclin) [98].

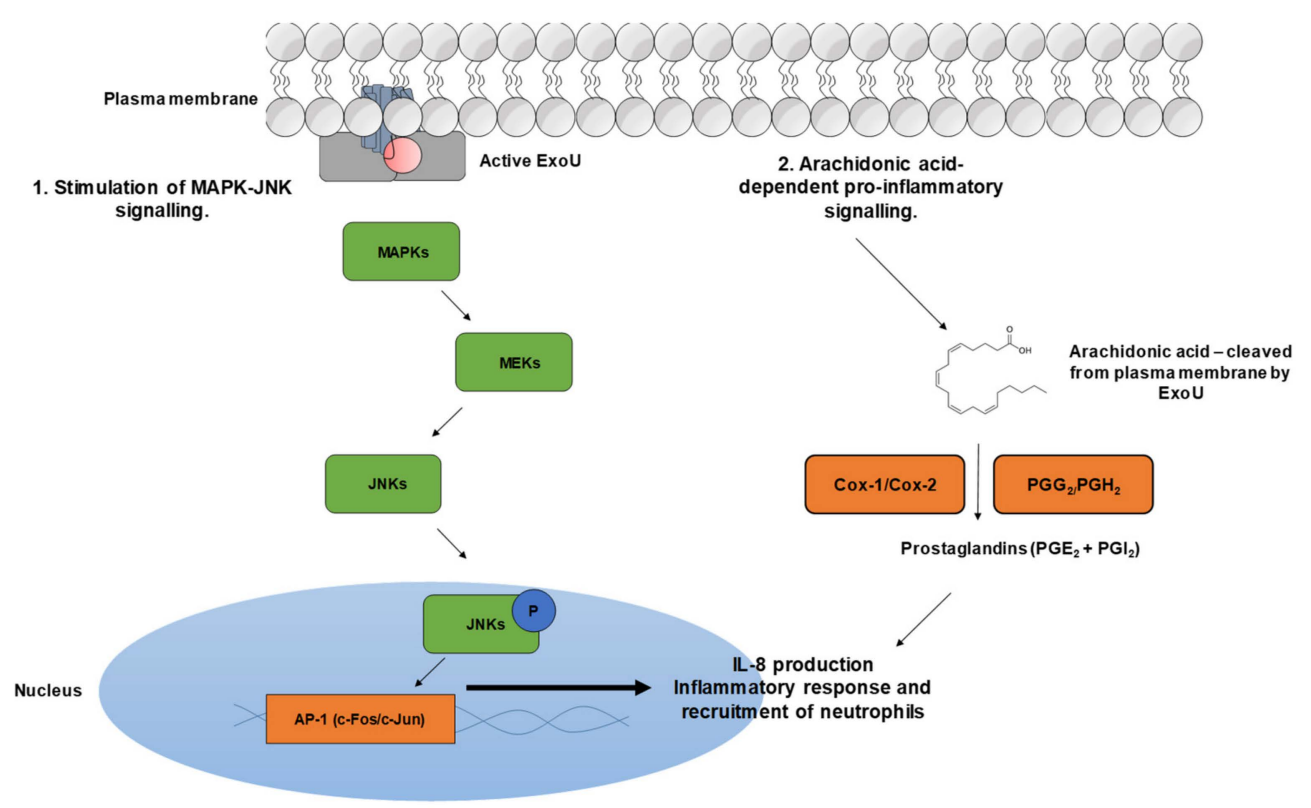

Figure 3. ExoU mediated activation of host cell signalling pathways. 1. The injected active ExoU stimulates the mitogen-activated protein kinase (MAPK) signalling cascade through an unknown mechanism. MEKs phosphorylate c-Jun NH2 terminal kinase (JNKs), which translocate to the nucleus and activate c-Fos and c-Jun transcription factors to stimulate the inflammatory response. 2. Active ExoU cleaves membrane phospholipids at the sn2 position to yield arachidonic acid. Arachidonic acid is converted to prostaglandins $\mathrm{PGE}_{2}$ and $\mathrm{PGI}_{2}$ by cyclooxygenases Cox- 1 and Cox-2 and endoperoxides $\mathrm{PGG}_{2}$ and $\mathrm{PGH}_{2}$.

\section{Pharmacological Targeting of the Bacterial Phospholipase ExoU}

Although the mechanisms of ExoU regulation are not fully understood, evidence for ubiquitin-binding as an activator and recruitment to the plasma membrane and oligomerisation followed by phospholipase A2 activity have been described in ExoU associated pathology [48,64]. These result in multiple dynamic conformational changes that could be targeted by small molecules to attenuate ExoU activity in clinical infections (Figure 1) [84,85,93,99].

In 2003, methyl arachidonyl fluorophosphonate (MAFP), an irreversible active site-directed promiscuous phospholipase inhibitor, was shown to protect Chinese Hamster Ovary (CHO) cells from ExoU mediated cell lysis after infection with the PA103 clinical isolate strain of P. aeruginosa [48]. 
The arachidonic acid analogue MAFP is a pan $\mathrm{PLA}_{2}$ inhibitor (Figure 4), which possess a phosphate group that covalently binds to the phospholipase catalytic serine residue. Although high concentrations of MAFP $(67.5 \mu \mathrm{M})$ were required to achieve measurable inhibition of $\mathrm{CHO}$ cell lysis, this was the first empirical proof that ExoU catalytic activity could be targeted by a small molecule inhibitor. This also validated the assertion that clinical phospholipase inhibitors, developed to target endogenous human phospholipases across a broad spectrum of diseases [100] could potentially have ExoU inhibiting activity. Such compounds could be repurposed to circumvent the pathological consequences of ExoU expression [101].

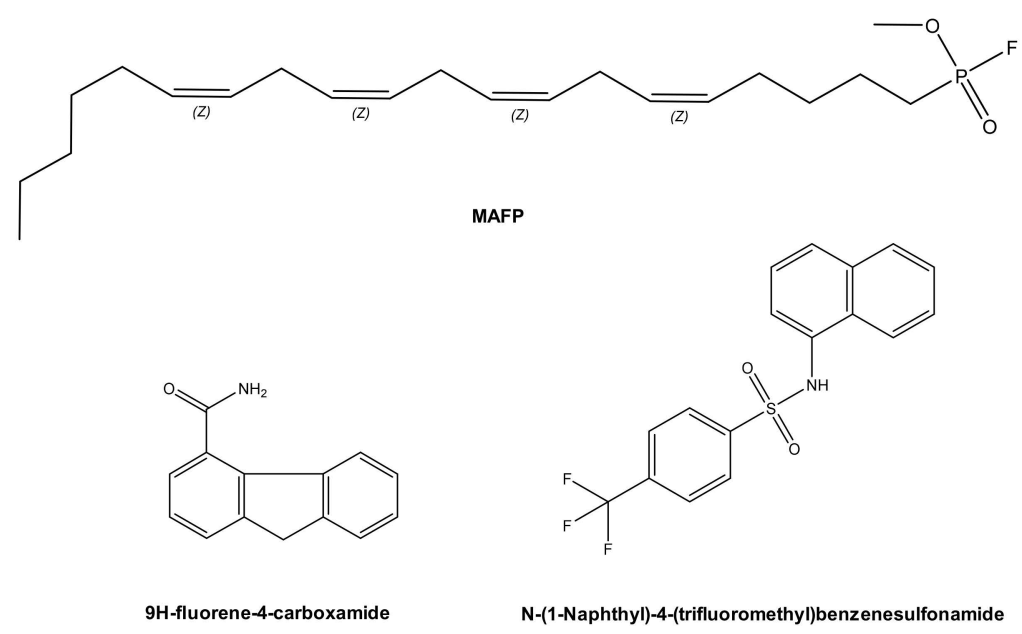

Figure 4. Prospective ExoU small molecule inhibitors. MAFP (Methoxy arachidonyl fluorophosphonate) is a non-specific $\mathrm{PLA}_{2}$ inhibitor, which is an analogue of arachidonic acid. Chemical structures of compounds previously distinguished to inhibit ExoU from two independent screens are also illustrated.

A subsequent study employed a high-throughput screen to discover compounds that could inhibit T3SS mediated cytotoxicity, with ExoU as the only cytotoxic effector [99]. By maintaining CHO cell viability in the presence of ExoU expressing strains of P. aeruginosa, 9H-fluorene-4-carboxamide, the designated pseudolipasin A (Figure 4), was identified as a promising compound lead. Further experimentation confirmed that pseudolipasin A did not inhibit type III secretion or type III injection of ExoU into $\mathrm{CHO}$ cells, but rather inhibited ExoU downstream of injection by the T3SS [99]. Relatively high concentrations of pseudolipasin A $(5-10 \mu \mathrm{M})$ were required to subvert the lytic effects of ExoU after $\mathrm{CHO}$ cells were infected with P. aeruginosa. This was in agreement with a $7 \mu \mathrm{M}$ reported $\mathrm{IC}_{50}$ value for inhibition for ExoU catalytic activity in vitro, which was determined by a phospholipase assay using recombinant ExoU expressed in E. coli.

In an independent screen, an arylsulphonamide was found to be effective at reducing the cytotoxic effect exerted by induced recombinant ExoU expression in yeast [102]. Saccharomyces cerevisiae were transformed with pDH105, which encoded ExoU cDNA. Upon induction with copper, ExoU expression led to S. cerevisiae lysis except in the presence of $5 \mu \mathrm{M}$ of a 'hit' arylsulfonamide compound (Figure 4) [102]. Synthesis of a small series of arylsulfonamides, comprising the N-(naphthalen-1-yl)benzenesulfonamide core, validated that this scaffold, when coupled to various commercially available sulfonyl chlorides, yielded compounds with differential abilities to mitigate ExoU mediated cell death [102]. Even though none were as effective as pseudolipasin A, the finding highlighted a novel pharmacological scaffold that could potentially be developed as an inhibitor of ExoU activity. A full biochemical exploration of the inhibitory mechanisms of these compounds remains to be undertaken, and it is not known whether or not these arylsulphonamides inhibit ExoU phospholipase activity in vitro.

Aside from modulating catalytic activity by binding to the ExoU active site, alternate modes of inhibition could occur. For instance, compound binding may inhibit ubiquitin-binding, conformational rearrangement, oligomerization, or phospholipid binding (Figure 1). It also remains to be tested 
whether or not the arylsulphonamide compounds can effectively protect mammalian cells after $P$. aeruginosa infection in vitro [102].

In order to capitalise on pseudolipasin A and arylsulphonamides as potential drug leads, further avenues of structure-activity relationships require exploration. As well as understanding mechanisms and conformations relevant to compound binding, structure-guided drug design could be used to modify pseudolipasin A [99] and the arylsulphonamides [102] to generate selective and more potent ExoU inhibitors. Analogues of the former compound, with a fluorene scaffold, appear to have cytotoxic effects on mammalian cells [102], which could preclude further development of pseudolipasin A as an ExoU inhibitor. Prospectively, the arylsulfonamide potential ExoU inhibitors display limited cytotoxicity in HEK293T cells [102]. Crystal structures of ExoU in complex with ubiquitin, phospholipid and/or compounds would be valuable for informing structure-guided design of such compounds. ExoU appears to be a dynamic protein, and the study of such conformations associated with cofactor and ligand binding might be explored by cryogenic electron microscopy (cryo EM). As ExoU is catalytically inactive when bound to its cognate chaperone SpcU [64], the already available co-crystal structures of ExoU and SpcU (PDB entries 3TU3 and 4AKX) $[64,68]$ could potentially serve as a foundation for structure-based design of inhibitors or peptides that mimic the interface between the $\mathrm{N}$-terminal domain of ExoU and SpcU. Perhaps the structures of ExoU and SpcU could be explored by in sillico-based screening approaches in order to discover novel potential ExoU ligands.

\subsection{Allosteric Inhibitors}

In order to find novel ExoU inhibitors, multiple screening strategies could be explored to evaluate compounds' ability to inhibit phospholipase A2 ExoU activity, translocation through the T3SS, and interaction with host co-factors. Allosteric inhibitors of ExoU may offer distinct efficacious and selective advantages over small molecules occupying the phospholipase substrate-binding pocket. Molecules that bind to conserved regions of the active site, encompassing the Serine-Aspartic acid catalytic dyad, may have limited selectivity and produced unwanted 'off-target' cytotoxic effects. Indeed, pseudolipasin A does not inhibit any of human group IID, IIE, V, X, or XII PLA 2 phospholipases tested [99]. Allosteric inhibitors exert their effects either by indirectly targeting catalytic activity or by modulating non-catalytic function, such as interactions with activating co-factors. They generally achieve better target precision through binding to specific residues, outside of the conserved active site. Such approaches have become popular for pharmacological targeting of disease-associated protein kinases [103]. Exploiting the ubiquitin-binding site of ExoU, which has been modelled in silico with the use of biophysical analysis and available crystallographic evidence [104], could serve as a point of allosteric inhibition that is selective and potent to ExoU activity inhibition. Such inhibitors could offer the advantage of being non-substrate competitive and, therefore, potentially, achieve superior potency. To this end, screening approaches to interrogate ExoU interaction with ubiquitin and $\mathrm{PIP}_{2}$ in the presence of prospective compounds would need to be developed.

An example of allosteric targeting of phospholipases is compound VU0364739. This is a phospholipase D2 (PLD2)-selective inhibitor, which occupies an allosteric site and blocks PIP $_{2}$ binding [105]. The selectivity of this compound was evidenced by a starkly increased IC $_{50}$ value for inhibition of the closely related PLD1 isoform of $1500 \mathrm{nM}$ compared to the $\mathrm{IC}_{50}$ value for PLD2 of $20 \mathrm{nM}$. VU0364739 is structurally similar to previously reported piperidine benzimidazolone-based allosteric inhibitors of AKT [106]. The PIP $_{2}$-binding site forms a hydrophobic pocket in the pleckstrin homology (PH) domain of PLD2, and the mode of inhibition is proposed to be akin to that facilitated by allosteric AKT compounds $[105,107]$. Perhaps a similar allosteric mechanism of inhibition of ExoU could be discovered, whereby certain classes of compound occupy a site within the C-terminal domain of ExoU in order to mitigate interaction with $\mathrm{PIP}_{2}$. 


\subsection{Ligand Repurposing Approaches}

The activities of phospholipase A2 enzymes is a contributing factor to various inflammatory pathological conditions, including arthritis, cardiovascular, and autoimmune diseases [100]. Modulation of their catalytic activity has become of major interest to pharmaceutical companies in recent years for the development of novel therapeutics [100]. De novo drug discovery, usually performed in the pharmaceutical industry, is an expensive and long process. Drug repurposing approaches have been used across a broad spectrum of diseases [108], where many "repurposed" drugs, such as antibiotics, antivirals, and kinase inhibitors, have had clinical success in treatment areas beyond their originally intended use. In a recent study, certain kinase inhibitors, including an inhibitor of PDK1, were able to function as an adjuvant in colistin-resistant bacteria, potentiating the antimicrobial effect in Gram-negative and Gram-positive bacteria [109]. This demonstrates that cross-reactivity of inhibitors originally intended to target eukaryotic proteins may be extended to target prokaryotic virulence effectors. Repurposing of clinical eukaryotic phospholipase inhibitors, to instead target the phospholipase A2 activity of ExoU, may have the advantage of entering the clinic more quickly, as they have already been tested for safety in human beings [101].

There may yet exist phospholipase A2 inhibitors that are cross-reactive with ExoU, which could be utilised when ExoU expression by P. aeruginosa is a driver of disease progression. Compounds exhibiting such cross-reactivity with ExoU could potentially serve as a foundation for the development of more selective ExoU inhibitors. Medicinal chemistry approaches, including in silico modelling, organic synthesis, and the study of structure-activity relationships may provide new chemicals as potential novel anti-ExoU pharmaceutical agents.

\section{Conclusions}

The type III secretion system of $P$. aeruginosa is used to inject the toxins ExoS, ExoT, ExoU, and ExoY into the cytosol of target eukaryotic cells during infection. ExoU is characterised as the major virulence factor responsible for acute epithelial injury in numerous diseases, including corneal, soft tissue, urinary tract, and respiratory tract infections [1-5]. Given the accessibility of the eye to the study of infections and topical treatment, as well as the predominance of ExoU-positive phenotypes in severe infection, it might be advantageous to use the cornea as a model to study the effect of drugs which target ExoU. In therapeutic contexts, as well as mitigating acute cellular damage, targeting ExoU may also have the advantage of a decreased risk for selecting resistance, as inhibition of ExoU mediated virulence may synergise with and allow the host immune system to respond better to the threat [96]. By subverting cellular signalling caused by ExoU, as well as ExoU phospholipase activity, neutrophils, of the innate immune system may be better equipped to respond to $P$. aeruginosa virulence [96]. Indeed, pharmacological targeting of ExoU may be compatible with antibiotic usage, whereby inhibitors of ExoU serve as an adjuvant therapy. In this way, ExoU inhibitors could mitigate the acute cytotoxic effects whilst conventional antibiotics eliminate the P. aeruginosa.

As well as new strategies to discover more compound leads, further structural evidence is required to direct the successful structure-guided design of current ExoU inhibitors. The development of biochemical assays should serve to discern the potential mechanisms of inhibition, be it by occupying the active site or preventing an interaction with an important activating co-factor.

Author Contributions: Conceptualisation: D.M.F., K.M., S.B.K. Writing: D.M.F. and K.M. contributed equally. Editing/proofreading: A.S.H., D.G.F., C.W., N.B., S.B.K.

Acknowledgments: The Fight for Sight (FFS) research charity funded this work.

Conflicts of Interest: The authors declare no conflict of interest.

\section{References}

1. Newman, J.W.; Floyd, R.V.; Fothergill, J.L. The contribution of Pseudomonas aeruginosa virulence factors and host factors in the establishment of urinary tract infections. FEMS Microbiol. Lett. 2017, 364, 1-12. [CrossRef] 
2. Stewart, R.M.K.; Wiehlmann, L.; Ashelford, K.E.; Preston, S.J.; Frimmersdorf, E.; Campbell, B.J.; Neal, T.J.; Hall, N.; Tuft, S.; Kaye, S.B.; et al. Genetic characterization indicates that a specific subpopulation of Pseudomonas aeruginosa is associated with keratitis infections. J. Clin. Microbiol. 2011, 49, 993-1003. [CrossRef] [PubMed]

3. Schulert, G.S.; Feltman, H.; Rabin, S.D.; Martin, C.G.; Battle, S.E.; Rello, J.; Hauser, A.R. Secretion of the toxin ExoU is a marker for highly virulent Pseudomonas aeruginosa isolates obtained from patients with hospital-acquired pneumonia. J. Infect. Dis. 2003, 188, 1695-1706. [CrossRef] [PubMed]

4. Roy-Burman, A.; Savel, R.H.H.; Racine, S.; Swanson, B.L.L.; Revadigar, N.S.S.; Fujimoto, J.; Sawa, T.; Frank, D.W.W.; Wiener-Kronish, J.P.; Roy-Burman, A.; et al. Type III Protein Secretion Is Associated with Death in Lower Respiratory and Systemic Pseudomonas aeruginosa Infections. J. Infect. Dis. 2002, 183, 1767-1774. [CrossRef] [PubMed]

5. Hauser, A.R.; Cobb, E.; Bodi, M.; Mariscal, D.; Valles, J.; Engel, J.N.; Rello, J.; Bodí, M.; Mariscal, D.; Vallés, J.; et al. Type III protein secretion is associated with poor clinical outcomes in patients with ventilator-associated pneumonia caused by Pseudomonas aeruginosa. Crit. Care Med. 2002, 30, 521-528. [CrossRef] [PubMed]

6. Migiyama, Y.; Yanagihara, K.; Kaku, N.; Harada, Y.; Yamada, K.; Nagaoka, K.; Morinaga, Y.; Akamatsu, N.; Matsuda, J.; Izumikawa, K.; et al. Pseudomonas aeruginosa bacteremia among immunocompetent and immunocompromised patients: Relation to initial antibiotic therapy and survival. Jpn. J. Infect. Dis. 2016, 69, 91-96. [CrossRef] [PubMed]

7. Bhagirath, A.Y.; Li, Y.; Somayajula, D.; Dadashi, M.; Badr, S.; Duan, K. Cystic fibrosis lung environment and Pseudomonas aeruginosa infection. BMC Pulm. Med. 2016, 16, 1-23. [CrossRef]

8. Fernández-Barat, L.; Ferrer, M.; De Rosa, F.; Gabarrús, A.; Esperatti, M.; Terraneo, S.; Rinaudo, M.; Li Bassi, G.; Torres, A. Intensive care unit-acquired pneumonia due to Pseudomonas aeruginosa with and without multidrug resistance. J. Infect. 2017, 74, 142-152. [CrossRef]

9. World Health Organisation. Global Priority List of Antibiotic-Resistant Bacteria to Guide Research, Discovery, and Development of New Antibitoics. Available online: https://www.who.int/medicines/publications/WHOPPL-Short_Summary_25Feb-ET_NM_WHO.pdf?ua=1 (accessed on 25 February 2017).

10. Klockgether, J.; Tümmler, B. Recent advances in understanding Pseudomonas aeruginosa as a pathogen. F1000Research 2017, 6, 1261. [CrossRef]

11. Finck-Barbançon, V.; Goranson, J.; Zhu, L.; Sawa, T.; Wiener-Kronish, J.P.; Fleiszig, S.M.J.; Wu, C.; Mende-Mueller, L.; Frank, D.W.; Finck-Barbançon, V.; et al. ExoU expression by Pseudomonas aeruginosa correlates with acute cytotoxicity and epithelial injury. Mol. Microbiol. 1997, 25, 547-557. [CrossRef]

12. Tam, C.; Lewis, S.E.; Li, W.Y.; Lee, E.; Evans, D.J.; Fleiszig, S.M.J. Mutation of the phospholipase catalytic domain of the Pseudomonas aeruginosa cytotoxin ExoU abolishes colonization promoting activity and reduces corneal disease severity. Exp. Eye Res. 2007, 85, 799-805. [CrossRef] [PubMed]

13. Park, M.-H.; Kim, S.Y.; Roh, E.Y.; Lee, H.S. Difference of Type 3 secretion system (T3SS) effector gene genotypes (exoU and exoS) and its implication to antibiotics resistances in isolates of Pseudomonas aeruginosa from chronic otitis media. Auris. Nasus. Larynx 2017, 44, 258-265. [CrossRef] [PubMed]

14. Galle, M.; Carpentier, I.; Beyaert, R. Structure and function of the Type III secretion system of Pseudomonas aeruginosa. Curr. Protein Pept. Sci. 2012, 13, 831-842. [CrossRef] [PubMed]

15. Monday, S.R.; Schiller, N.L. Alginate synthesis in Pseudomonas aeruginosa: The role of AlgL (alginate lyase) and AlgX. J. Bacteriol. 1996, 178, 625-632. [CrossRef]

16. Poole, K. Efflux-mediated antimicrobial resistance. Antibiot. Discov. Dev. 2005, 56, 20-51. [CrossRef]

17. Thibodeaux, B.A.; Caballero, A.R.; Marquart, M.E.; Tommassen, J.; O'Callaghan, R.J. Corneal Virulence of Pseudomonas aeruginosa Elastase B and Alkaline Protease Produced by Pseudomonas putida. Curr. Eye Res. 2007, 32, 373-386. [CrossRef]

18. Hong, Y.; Ghebrehiwet, B. Effect of Pseudomonas aeruginosa elastase and alkaline protease on serum complement and isolated components C1q and C3. Clin. Immunol. Immunopathol. 1992, 62, 133-138. [CrossRef]

19. Parmely, M.; Gale, A.; Clabaugh, M.; Horvat, R.; Zhou, W.W. Proteolytic inactivation of cytokines by Pseudomonas aeruginosa. Infect. Immun. 1990, 58, 3009-3014.

20. Bahl, C.D.; Morisseau, C.; Bomberger, J.M.; Stanton, B.A.; Hammock, B.D.; O’Toole, G.A.; Madden, D.R. Crystal structure of the cystic fibrosis transmembrane conductance regulator inhibitory factor cif reveals novel active-site features of an epoxide hydrolase virulence factor. J. Bacteriol. 2010, 192, 1785-1795. [CrossRef] 
21. Ballok, A.E.; O'Toole, G.A. Pouring salt on a wound: Pseudomonas aeruginosa virulence factors alter Na+ and Cl-flux in the lung. J. Bacteriol. 2013, 195, 4013-4019. [CrossRef]

22. Flitter, B.A.; Hvorecny, K.L.; Ono, E.; Eddens, T.; Yang, J.; Kwak, D.H.; Bahl, C.D.; Hampton, T.H.; Morisseau, C.; Hammock, B.D.; et al. Pseudomonas aeruginosa sabotages the generation of host proresolving lipid mediators. Proc. Natl. Acad. Sci. USA 2017, 114, 136-141. [CrossRef] [PubMed]

23. Bomberger, J.M.; Ely, K.H.; Bangia, N.; Ye, S.; Green, K.A.; Green, W.R.; Enelow, R.I.; Stanton, B.A. Pseudomonas aeruginosa Cif protein enhances the ubiquitination and proteasomal degradation of the transporter associated with antigen processing (TAP) and reduces major histocompatibility complex (MHC) class I antigen presentation. J. Biol. Chem. 2014, 289, 152-162. [CrossRef] [PubMed]

24. Michalska, M.; Wolf, P. Pseudomonas Exotoxin A: Optimized by evolution for effective killing. Front. Microbiol. 2015, 6, 1-7. [CrossRef] [PubMed]

25. Rocha, C.L.; Coburn, J.; Rucks, E.A.; Olson, J.C. Characterization of Pseudomonas aeruginosa exoenzyme S as a bifunctional enzyme in J774a.1 macrophages. Infect. Immun. 2003, 71, 5296-5305. [CrossRef]

26. Sun, J.; Barbieri, J.T. Pseudomonas aeruginosa ExoT ADP-ribosylates CT10 regulator of kinase (Crk) proteins. J. Biol. Chem. 2003, 278, 32794-32800. [CrossRef]

27. Barbieri, J.T.; Sun, J. Pseudomonas aeruginosa ExoS and ExoT. In Reviews of Physiology, Biochemistry and Pharmacology; Springer: Berlin/Heidelberg, Germany, 2004; pp. 79-92.

28. Galle, M.; Jin, S.; Bogaert, P.; Haegman, M.; Vandenabeele, P.; Beyaert, R. The pseudomonas aeruginosa type III secretion system has an exotoxin $\mathrm{S} / \mathrm{T} / \mathrm{Y}$ independent pathogenic role during acute lung infection. PLoS ONE 2012, 7, e41547. [CrossRef]

29. Sato, H.; Frank, D.W.; Hillard, C.J.; Feix, J.B.; Pankhaniya, R.R.; Moriyama, K.; Finck-Barbancon, V.; Buchaklian, A.; Lei, M.; Long, R.M.; et al. The mechanism of action of the Pseudomonas aeruginosa-encoded type III cytotoxin, ExoU. EMBO J. 2003, 22, 2959-2969. [CrossRef]

30. Anderson, D.M.; Schmalzer, K.M.; Sato, H.; Casey, M.; Terhune, S.S.; Haas, A.L.; Feix, J.B.; Frank, D.W. Ubiquitin and ubiquitin-modified proteins activate the Pseudomonas aeruginosa T3SS cytotoxin, ExoU. Mol. Microbiol. 2011, 82, 1454-1467. [CrossRef]

31. Miao, E.A.; Andersen-Nissen, E.; Warren, S.E.; Aderem, A. TLR5 and Ipaf: Dual sensors of bacterial flagellin in the innate immune system. Semin. Immunopathol. 2007, 29, 275-288. [CrossRef]

32. Spencer, J.; Murphy, L.M.; Conners, R.; Sessions, R.B.; Gamblin, S.J. Crystal structure of the lasA virulence factor from Pseudomonas aeruginosa: Substrate specificity and mechanism of M23 metallopeptidases. J. Mol. Biol. 2010, 396, 908-923. [CrossRef]

33. Kessler, E.; Safrin, M.; Gustin, J.K.; Ohman, D.E. Elastase and the LasA protease of Pseudomonas aeruginosa are secreted with their propeptides. J. Biol. Chem. 1998, 273, 30225-30231. [CrossRef] [PubMed]

34. Wargo, M.J.; Ho, T.C.; Gross, M.J.; Whittaker, L.A.; Hogan, D.A. GbdR regulates Pseudomonas aeruginosa plcH and pchP transcription in response to choline catabolites. Infect. Immun. 2009, 77, 1103-1111. [CrossRef] [PubMed]

35. Ostroff, R.M.; Vasil, A.I.; Vasil, M.L. Molecular comparison of a nonhemolytic and a hemolytic phospholipase C from Pseudomonas aeruginosa. J. Bacteriol. 1990, 172, 5915-5923. [CrossRef] [PubMed]

36. Spencer, C.; Brown, H.A. Biochemical characterization of a pseudomonas aeruginosa phospholipase d. Biochemistry 2015, 54, 1208-1218. [CrossRef] [PubMed]

37. Jiang, F.; Waterfield, N.R.; Yang, J.; Yang, G.; Jin, Q. A Pseudomonas aeruginosa type VI secretion phospholipase D effector targets both prokaryotic and eukaryotic cells. Cell Host Microbe 2014, 15, 600-610. [CrossRef]

38. Traidej, M.; Marquart, M.E.; Caballero, A.R.; Thibodeaux, B.A.; O'Callaghan, R.J. Identification of the active site residues of Pseudomonas aeruginosa protease IV: Importance of enzyme activity in autoprocessing and activation. J. Biol. Chem. 2003, 278, 2549-2553. [CrossRef]

39. Park, S.J.; Kim, S.K.; So, Y.I.; Park, H.Y.; Li, X.H. Protease IV, a quorum sensing-dependent protease of Pseudomonas aeruginosa modulates insect innate immunity. Mol. Microbiol. 2014, 94, 1298-1314. [CrossRef]

40. Lau, G.W.; Ran, H.; Kong, F.; Hassett, D.J.; Mavrodi, D. Pseudomonas aeruginosa pyocyanin is critical for lung infection in mice. Infect. Immun. 2004, 72, 4275-4278. [CrossRef]

41. Davey, M.E.; Caiazza, N.C.; O'Toole, G.A. Rhamnolipid surfactant production affects biofilm architecture in Pseudomonas aeruginosa PAO1. J. Bacteriol. 2003, 185, 1027-1036. [CrossRef] 
42. Jiang, F.; Wang, X.; Wang, B.; Chen, L.; Zhao, Z.; Waterfield, N.R.; Yang, G.; Jin, Q. The Pseudomonas aeruginosa Type VI Secretion PGAP1-like Effector Induces Host Autophagy by Activating Endoplasmic Reticulum Stress. Cell Rep. 2016, 16, 1502-1509. [CrossRef]

43. Borkar, D.S.; Fleiszig, S.M.J.; Leong, C.; Lalitha, P.; Srinivasan, M.; Ghanekar, A.A.; Tam, C.; Li, W.Y.; Zegans, M.E.; McLeod, S.D.; et al. Association between cytotoxic and invasive pseudomonas aeruginosa and clinical outcomes in bacterial keratitis. JAMA Ophthalmol. 2013, 131, 147-153. [CrossRef] [PubMed]

44. Goehring, U.M.; Schmidt, G.; Pederson, K.J.; Aktories, K.; Barbieri, J.T. The N-terminal domain of Pseudomonas aeruginosa exoenzyme $\mathrm{S}$ is a GTPase- activating protein for Rho GTPases. J. Biol. Chem. 1999, 274, 36369-36372. [CrossRef]

45. Vareechon, C.; Zmina, S.E.; Karmakar, M.; Pearlman, E.; Rietsch, A. Pseudomonas aeruginosa Effector ExoS Inhibits ROS Production in Human Neutrophils. Cell Host Microbe 2017, 21, 611-618. [CrossRef] [PubMed]

46. Kaufman, M.R.; Jia, J.; Zeng, L.; Ha, U.; Chow, M.; Jin, S. Pseudomonas aeruginosa mediated apoptosis requires the ADP-ribosylating activity of ExoS. Microbiology 2000, 146, 2531-2541. [CrossRef] [PubMed]

47. Sato, H.; Frank, D.W. ExoU is a potent intracellular phospholipase. Mol. Microbiol. 2004, 53, 1279-1290. [CrossRef]

48. Phillips, R.M.; Six, D.A.; Dennis, E.A.; Ghosh, P. In vivo phospholipase activity of the Pseudomonas aeruginosa cytotoxin ExoU and protection of mammalian cells with phospholipase A2 inhibitors. J. Biol. Chem. 2003, 278, 41326-41332. [CrossRef] [PubMed]

49. Pankhaniya, R.R.; Tamura, M.; Allmond, L.R.; Moriyama, K.; Ajayi, T.; Wiener-Kronish, J.P.; Sawa, T. Pseudomonas aeruginosa causes acute lung injury via the catalytic activity of the patatin-like phospholipase domain of ExoU. Crit. Care Med. 2004, 32, 2293-2299. [CrossRef]

50. El Solh, A.A.; Akinnusi, M.E.; Wiener-Kronish, J.P.; Lynch, S.V.; Pineda, L.A.; Szarpa, K. Persistent infection with Pseudomonas aeruginosa in ventilator-associated pneumonia. Am. J. Respir. Crit. Care Med. 2008, 178, 513-519. [CrossRef]

51. Diaz, M.H.; Shaver, C.M.; King, J.D.; Musunuri, S.; Kazzaz, J.A.; Hauser, A.R. Pseudomonas aeruginosa induces localized immunosuppression during pneumonia. Infect. Immun. 2008, 76, 4414-4421. [CrossRef]

52. Engel, J.; Balachandran, P. Role of Pseudomonas aeruginosa type III effectors in disease. Curr. Opin. Microbiol. 2009, 12, 61-66. [CrossRef]

53. Rabin, S.D.P.P.; Hauser, A.R. Functional regions of the Pseudomonas aeruginosa cytotoxin ExoU. Infect. Immun. 2005, 73, 573-582. [CrossRef] [PubMed]

54. Apodaca, G.; Bomsel, M.; Lindstedt, R.; Engel, J.; Frank, D.; Mostov, K.E.; Wiener- Kronish, J. Characterization of Pseudomonas aeruginosa-induced MDCK cell injury: Glycosylation-defective host cells are resistant to bacterial killing. Infect. Immun. 1995, 63, 1541-1551. [PubMed]

55. Wiener-Kronish, J.P.; Sakuma, T.; Kudoh, I.; Pittet, J.F.; Frank, D.; Dobbs, L.; Vasil, M.L.; Matthay, M.A. Alveolar epithelial injury and pleural empyema in acute P. aeruginosa pneumonia in anesthetized rabbits. J. Appl. Physiol. 1993, 74, 1661-1669. [CrossRef] [PubMed]

56. Pittet, J.F.; Wiener-Kronish, J.P.; McElroy, M.C.; Folkesson, H.G.; Matthay, M.A. Stimulation of lung epithelial liquid clearance by endogenous release of catecholamines in septic shock in anesthetized rats. J. Clin. Invest. 1994, 94, 663-671. [CrossRef] [PubMed]

57. Jung Kang, P.; Hauser, A.R.; Apodaca, G.; Fleiszig, S.M.J.; Wiener-Kronish, J.; Mostov, K.; Engel, J.N. Identification of Pseudomonas aeruginosa genes required for epithelial cell injury. Mol. Microbiol. 1997, 24, 1249-1262. [CrossRef] [PubMed]

58. Sato, H.; Feix, J.B.; Frank, D.W. Identification of superoxide dismutase as a cofactor for the pseudomonas type III toxin, ExoU. Biochemistry 2006, 45, 10368-10375. [CrossRef] [PubMed]

59. Stirling, F.R.; Cuzick, A.; Kelly, S.M.; Oxley, D.; Evans, T.J. Eukaryotic localization, activation and ubiquitinylation of a bacterial type III secreted toxin. Cell. Microbiol. 2006, 8, 1294-1309. [CrossRef]

60. Anderson, D.M.; Sato, H.; Dirck, A.T.; Feix, J.B.; Frank, D.W. Ubiquitin activates patatin-like phospholipases from multiple bacterial species. J. Bacteriol. 2015, 197, 529-541. [CrossRef]

61. Finck-Barbancon, V.; Frank, D.W. Multiple domains are required for the toxic activity of Pseudomonas aeruginosa ExoU. J. Bacteriol. 2001, 183, 4330-4344. [CrossRef]

62. Parsot, C.; Hamiaux, C.; Page, A.L. The various and varying roles of specific chaperones in type III secretion systems. Curr. Opin. Microbiol. 2003, 6, 7-14. [CrossRef] 
63. Akeda, Y.; Galán, J.E. Chaperone release and unfolding of substrates in type III secretion. Nature 2005, 437, 911-915. [CrossRef] [PubMed]

64. Halavaty, A.S.; Borek, D.; Tyson, G.H.; Veesenmeyer, J.L.; Shuvalova, L.; Minasov, G.; Otwinowski, Z.; Hauser, A.R.; Anderson, W.F. Structure of the Type III Secretion Effector Protein ExoU in Complex with Its Chaperone SpcU. PLoS ONE 2012, 7, e49388. [CrossRef] [PubMed]

65. Rydel, T.J.; Williams, J.M.; Krieger, E.; Moshiri, F.; Stallings, W.C.; Brown, S.M.; Pershing, J.C.; Purcell, J.P.; Alibhai, M.F. The crystal structure, mutagenesis, and activity studies reveal that patan is a lipid acyl hydrolase with a Ser-Asp catalytic dyad. Biochemistry 2003, 42, 6696-6708. [CrossRef] [PubMed]

66. Hirschberg, H.J.H.B.; Simons, J.W.F.A.; Dekker, N.; Egmond, M.R. Cloning, expression, purification and characterization of patatin, a novel phospholipase A. Eur. J. Biochem. 2001, 268, 5037-5044. [CrossRef]

67. Dessen, A.; Tang, J.; Schmidt, H.; Stahl, M.; Clark, J.D.; Seehra, J.; Somers, W.S. Crystal structure of human cytosolic phospholipase A2 reveals a novel topology and catalytic mechanism. Cell 1999, 97, 349-360. [CrossRef]

68. Gendrin, C.; Contreras-Martel, C.; Bouillot, S.S.; Elsen, S.; Lemaire, D.; Skoufias, D.A.; Huber, P.; Attree, I.; Dessen, A.A. Structural basis of cytotoxicity mediated by the type III secretion toxin ExoU from Pseudomonas aeruginosa. PLoS Pathog. 2012, 8, e1002637. [CrossRef]

69. Geissler, B.; Tungekar, R.; Satchell, K.J.F. Identification of a conserved membrane localization domain within numerous large bacterial protein toxins. Proc. Natl. Acad. Sci. USA 2010, 107, 5581-5586. [CrossRef]

70. Geissler, B.; Ahrens, S.; Satchell, K.J.F. Plasma membrane association of three classes of bacterial toxins is mediated by a basic-hydrophobic motif. Cell. Microbiol. 2012, 14, 286-298. [CrossRef]

71. Yahr, T.L.; Barbieri, J.T.; Frank, D.W. Genetic relationship between the 53- and 49-kilodalton forms of exoenzyme $S$ from Pseudomonas aeruginosa. J. Bacteriol. 1996, 178, 1412-1419. [CrossRef]

72. Pastor, A.; Chabert, J.; Louwagie, M.; Garin, J.; Attree, I. PscF is a major component of the Pseudomonas aeruginosa type III secretion needle. FEMS Microbiol. Lett. 2005, 253, 95-101. [CrossRef]

73. Mueller, C.A.; Broz, P.; Cornelis, G.R. The type III secretion system tip complex and translocon. Mol. Microbiol. 2008, 68, 1085-1095. [CrossRef] [PubMed]

74. Sarker, M.R.; Neyt, C.; Stainier, I.; Cornelis, G.R. The Yersinia Yop virulon: Lcr V is required to extrusion of the translocators YopB and YopD. J. Bacteriol. 1998, 180, 1207-1214. [PubMed]

75. Halder, P.K.; Roy, C.; Datta, S. Structural and functional characterization of type three secretion system ATPase PscN and its regulator PscL from Pseudomonas aeruginosa. Proteins Struct. Funct. Bioinform. 2019, 87, 276-288. [CrossRef] [PubMed]

76. Yahr, T.L.; Goranson, J.; Frank, D.W. Exoenzyme of S of Pseudomonas aeruginosa is secreted by a type III pathway. Mol. Microbiol. 1996, 22, 991-1003. [CrossRef]

77. Galán, J.E.; Lara-Tejero, M.; Marlovits, T.C.; Wagner, S. Bacterial Type III Secretion Systems: Specialized Nanomachines for Protein Delivery into Target Cells. Annu. Rev. Microbiol. 2014, 68, 415-438. [CrossRef]

78. Kim, J.; Ahn, K.; Min, S.; Jia, J.; Ha, U.; Wu, D.; Jin, S. Factors triggering type III secretion in Pseudomonas aeruginosa. Microbiology 2005, 151, 3575-3587. [CrossRef]

79. Williams McMackin, E.A.; Djapgne, L.; Corley, J.M.; Yahr, T.L. Fitting Pieces into the Puzzle of Pseudomonas aeruginosa Type III Secretion System Gene Expression. J. Bacteriol. 2019, 201, e00209-19. [CrossRef]

80. Zheng, Z.; Chen, G.; Joshi, S.; Brutinel, E.D.; Yahr, T.L.; Chen, L. Biochemical characterization of a regulatory cascade controlling transcription of the Pseudomonas aeruginosa type III secretion system. J. Biol. Chem. 2007, 62, 631-640.

81. Thibault, J.; Faudry, E.; Ebel, C.; Attree, I.; Elsen, S. Anti-activator ExsD forms a 1:1 complex with ExsA to inhibit transcription of type III secretion operons. J. Biol. Chem. 2009, 284, 15762-15770. [CrossRef]

82. Urbanowski, M.L.; Lykken, G.L.; Yahr, T.L. A secreted regulatory protein couples transcription to the secretory activity of the Pseudomonas aeruginosa type III secretion system. Proc. Natl. Acad. Sci. USA 2005, 102, 9930-9935. [CrossRef]

83. Lykken, G.L.; Chen, G.Z.; Brutinel, E.D.; Chen, L.; Yahr, T.L. Characterization of ExsC and ExsD self-association and heterocomplex formation. J. Bacteriol. 2006, 188, 6832-6840. [CrossRef]

84. Tessmer, M.H.; Anderson, D.M.; Buchaklian, A.; Frank, D.W.; Feix, J.B. Cooperative substrate-cofactor interactions and membrane localization of the bacterial phospholipase A 2 (PLA 2 ) enzyme, ExoU. J. Biol. Chem. 2017, 292, 3411-3419. [CrossRef] [PubMed] 
85. Tyson, G.H.; Halavaty, A.S.; Kim, H.; Geissler, B.; Agard, M.; Satchell, K.J.; Cho, W.; Anderson, W.F.; Hauser, A.R. A novel phosphatidylinositol 4,5-bisphosphate binding domain mediates plasma membrane localization of ExoU and other patatin-like phospholipases. J. Biol. Chem. 2015, 290, 2919-2937. [CrossRef] [PubMed]

86. Tyson, G.H.; Hauser, A.R. Phosphatidylinositol 4,5-bisphosphate is a novel coactivator of the Pseudomonas aeruginosa cytotoxin ExoU. Infect. Immun. 2013, 81, 2873-2881. [CrossRef]

87. Wenk, M.R.; Lucast, L.; Di Paolo, G.; Romanelli, A.J.; Suchy, S.F.; Nussbaum, R.L.; Cline, G.W.; Shulman, G.I.; McMurray, W.; De Camilli, P. Phosphoinositide profiling in complex lipid mixtures using electrospray ionization mass spectrometry. Nat. Biotechnol. 2003, 21, 813-817. [CrossRef]

88. Ferrell, J.E.; Huests, W.H. Phosphoinositide metabolism and the morphology of human erythrocytes. J. Cell Biol. 1984, 98, 1992-1998. [CrossRef]

89. Raucher, D.; Stauffer, T.; Chen, W.; Shen, K.; Guo, S.; York, J.D.; Sheetz, M.P.; Meyer, T. Phosphatidylinositol 4,5-bisphosphate functions as a second messenger that regulates cytoskeleton-plasma membrane adhesion. Cell 2000, 100, 221-228. [CrossRef]

90. Di Paolo, G.; De Camilli, P. Phosphoinositides in cell regulation and membrane dynamics. Nature 2006, 443, 651-657. [CrossRef]

91. Saarikangas, J.; Zhao, H.; Lappalainen, P. Regulation of the actin cytoskeleton-plasma membrane interplay by phosphoinositides. Physiol. Rev. 2010, 90, 259-289. [CrossRef] [PubMed]

92. Sato, H.; Frank, D.W. Intoxication of host cells by the T3SS phospholipase ExoU: PI(4,5)P2-associated, cytoskeletal collapse and late phase membrane blebbing. PLoS ONE 2014, 9, e103127. [CrossRef]

93. Zhang, A.; Veesenmeyer, J.L.; Hauser, A.R. Phosphatidylinositol 4,5-Bisphosphate-Dependent Oligomerization of the Pseudomonas aeruginosa Cytotoxin ExoU. Infect. Immun. 2018, 86, 2873-2881. [CrossRef] [PubMed]

94. Rabin, S.D.P.; Veesenmeyer, J.L.; Bieging, K.T.; Hauser, A.R. A C-terminal domain targets the Pseudomonas aeruginosa cytotoxin ExoU to the plasma membrane of host cells. Infect. Immun. 2006, 74, 2552-2561. [CrossRef] [PubMed]

95. Keshet, Y.; Seger, R. The MAP kinase signaling cascades: A system of hundreds of components regulates a diverse array of physiological functions. Methods Mol. Biol. 2010, 661, 3-38. [PubMed]

96. Cuzick, A.; Stirling, F.R.; Lindsay, S.L.; Evans, T.J. The type III pseudomonal exotoxin U activates the c-Jun NH 2 -terminal kinase pathway and increases human epithelial interleukin-8 production. Infect. Immun. 2006, 74, 4104-4113. [CrossRef]

97. McMorran, B.; Town, L.; Costelloe, E.; Palmer, J.; Engel, J.; Hume, D.; Wainwright, B. Effector ExoU from the type III secretion system is an important modulator of gene expression in lung epithelial cells in response to Pseudomonas aeruginosa infection. Infect. Immun. 2003, 71, 6035-6044. [CrossRef]

98. Saliba, A.M.; Nascimento, D.O.; Silva, M.C.A.; Assis, M.C.; Gayer, C.R.M.; Raymond, B.; Coelho, M.G.P.; Marques, E.A.; Touqui, L.; Albano, R.M.; et al. Eicosanoid-mediated proinflammatory activity of pseudomonas aeruginosa ExoU. Cell. Microbiol. 2005, 7, 1811-1822. [CrossRef]

99. Lee, V.T.; Pukatzki, S.; Sato, H.; Kikawada, E.; Kazimirova, A.A.; Huang, J.; Li, X.; Arm, J.P.; Frank, D.W.; Lory, S. Pseudolipasin A is a specific inhibitor for phospholipase A2 activity of Pseudomonas aeruginosa cytotoxin ExoU. Infect. Immun. 2007, 75, 1089-1098. [CrossRef]

100. Nikolaou, A.; Kokotou, M.G.; Vasilakaki, S.; Kokotos, G. Small-molecule inhibitors as potential therapeutics and as tools to understand the role of phospholipases A 2. Biochim. Biophys. Acta-Mol. Cell Biol. Lipids 2019, 1864, 941-956. [CrossRef]

101. Bao, J.; Marathe, B.; Govorkova, E.A.; Zheng, J.J. Drug Repurposing Identifies Inhibitors of Oseltamivir-Resistant Influenza Viruses. Angew. Chemie-Int. Ed. 2016, 55, 3438-3441. [CrossRef]

102. Kim, D.; Baek, J.; Song, J.; Byeon, H.; Min, H.; Min, K.H. Identification of arylsulfonamides as ExoU inhibitors. Bioorg. Med. Chem. Lett. 2014, 24, 3823-3825. [CrossRef]

103. Leroux, A.E.; Schulze, J.O.; Biondi, R.M. AGC kinases, mechanisms of regulation and innovative drug development. Semin. Cancer Biol. 2018, 48, 1-17. [CrossRef] [PubMed]

104. Tessmer, M.H.; Anderson, D.M.; Pickrum, A.M.; Riegert, M.O.; Moretti, R.; Meiler, J.; Feix, J.B.; Frank, D.W. Identification of a ubiquitin-binding interface using Rosetta and DEER. Proc. Natl. Acad. Sci. USA 2018, 115, 525-530. [CrossRef] [PubMed] 
105. Brown, H.A.; Thomas, P.G.; Lindsley, C.W. Targeting phospholipase D in cancer, infection and neurodegenerative disorders. Nat. Rev. Drug Discov. 2017, 16, 351-367. [CrossRef] [PubMed]

106. Lindsley, C.W.; Zhao, Z.; Leister, W.H.; Robinson, R.G.; Barnett, S.F.; Defeo-Jones, D.; Jones, R.E.; Hartman, G.D.; Huff, J.R.; Huber, H.E.; et al. Allosteric Akt (PKB) inhibitors: Discovery and SAR of isozyme selective inhibitors. Bioorganic Med. Chem. Lett. 2005, 15, 761-764. [CrossRef] [PubMed]

107. Barnett, S.F.; Defeo-Jones, D.; Fu, S.; Hancock, P.J.; Haskell, K.M.; Jones, R.E.; Kahana, J.A.; Kral, A.M.; Leander, K.; Lee, L.L.; et al. Identification and characterization of pleckstrin-homology-domain-dependent and isoenzyme-specific Akt inhibitors. Biochem. J. 2005, 385, 399-408. [CrossRef] [PubMed]

108. Schein, C.H. Repurposing approved drugs on the pathway to novel therapies. Med. Res. Rev. 2019. [CrossRef]

109. Barker, W.; Nemeth, A.; Brackett, S.; Basak, A.; Chandler, C.E.; Jania, L.; Zuercher, W.; Melander, R.J.; Koller, B.; Ernst, R.K.; et al. Repurposing Eukaryotic Kinase Inhibitors as Colistin Adjuvants in Gram-negative Bacteria. ACS Infect. Dis. 2019, 5, 1764-1771. [CrossRef]

(C) 2019 by the authors. Licensee MDPI, Basel, Switzerland. This article is an open access article distributed under the terms and conditions of the Creative Commons Attribution (CC BY) license (http://creativecommons.org/licenses/by/4.0/). 